Keywords: PTSD; DRD2; Child trauma; Taq A1;

Risk factor; Polymorphism.

\title{
The A1 allele of the DRD2 TaqA1/A2 polymorphism as risk factor for PTSD
}

\author{
Ahmed Rady* \\ Adel Elsheshai* \\ Mohammed Mokhtar** \\ Heba Abou el Wafa* \\ Osama Elkholy* \\ * Department of Psychiatry, \\ Alexandria University \\ ** Department of Genetics, Institute \\ of Clinical researches, Alexandria \\ EGYPT
}

\begin{abstract}
Background and Objectives: Dopaminergic neurotransmission is implicated in stress responses. The dopamine D2 receptor gene (DRD2) has been studied by the authors to assess its possible role as a predictor of those who are at a higher risk to develop PTSD after major psychological trauma.

Methods: Over one year period 75 children and adolescents 6-18 yrs of age who had been exposed to moderate to severe burns were recruited from the burn unit at the Alexandria University Hospital for the study. Patients and their family were interviewed within the first 10 days of exposure. After signing a written consent form a $2 \mathrm{ml}$ blood sample was obtained for genetic studies of the TaqA1/A2 polymorphism site of the DRD2 gene. Patients were reevaluated three and six months later for assessment of PTSD.

Results: Among the 75 children recruited in the study, 26 died due to their burn injury, 19 dropped out as parents refused follow up and 30 continued the study follow up visits. Fourteen carried the A1A2 genotype. Of these 11 (78.6\%) developed PTSD. Sixteen carried the A2A2 genotype. Of these only one child (6.3\%) developed PTSD. The results were significant at $\mathrm{p}<0.001$ with a relative risk 12.5 .

Conclusions: Following exposure to severe stress, the presence of the Taq A1 allele of the DRD2 gene results in a significant increase in the risk of developing PTSD.
\end{abstract}

Received: 5 May 2010

Revised: 28 December 2010

Accepted: 25 February 2011 


\section{Introduction}

Exposure to severe stress increases dopamine discharge in the medial prefrontal cortex while decreasing dopamine firing in nucleus accumbens ${ }^{1-3}$. Lesions of the amygdala in a conditioned stress model inhibit dopamine activation in the medial prefrontal cortex after stress, such findings highlight the probable role of the amygdala in controlling stress-induced dopamine activation and integrating the behavioral and neuroendocrine components of the stress response ${ }^{4}$. There is preclinical evidence that the susceptibility of the mesocortical dopamine system to stress activation may be in part genetically determined. It has been suggested that excessive mesocortical dopamine release by stressful events may represent a vulnerability to depression and favor helpless reactions through an inhibition of subcortical dopamine transmission ${ }^{1,3}$. These observations may be due to the effect of dopamine on reward mechanisms.

On the other hand, lesions of dopamine neurons in the medial prefrontal cortex delay extinction of the conditioned fear stress response (no effect on acquisition), indicating that prefrontal dopamine neurons are involved in facilitating extinction of the fear response. This suggests that inhibited prefrontal cortical dopamine results in the preservation of fear produced by a conditioned stressor, a similar organization is hypothesized in PTSD ${ }^{5}$. It has been suggested that there is an optimal range for stress-induced increase in cortical dopamine released in the medial prefrontal cortex to facilitate adaptive behavioral responses. Too much dopamine release in the medial prefrontal cortex produces cognitive impairment; an inhibition in dopamine activity in the nucleus accumbens results in abnormalities in motivation and reward mechanisms.
Insufficient prefrontal cortical dopamine release delays extinction of conditioned fear ${ }^{6}$.

Substantial evidence highlight a genetic contribution to PTSD based on family ${ }^{7}$, twin $^{8}$ and adoption ${ }^{9}$ models of genetic epidemiology. There are two important PTSD candidate genes that directly affect the dopamine system: the dopamine receptor gene (DRD2) and the dopamine transporter gene (DAT). The D2 dopamine receptor (DRD2) minor A1 allele has already been linked to ADHD, Tourette's syndrome, conduct disorder and substance abuse ${ }^{10}$. Literature tackling the probable implication of DRD2 receptor A1 Allele in PTSD give contrasting results. Some authors working on the role of DRD2 in PTSD, reported a significant association between the presence of the DRD2 A1 allele and PTSD ${ }^{11}$. Others do not report a positive association ${ }^{12}$. The purpose of our work is to assess the association between A1A2 genotype of Dopamine receptor type 2 (DRD2) gene and risk for PTSD after major stress.

\section{Subjects and Methods}

75 children and adolescents exposed to moderate or major burn according to the classification of burn severity ${ }^{13}$ were recruited over one year period from the burn unit of Alexandria University Hospital, 26 of them died during hospitalization or during the six month period of follow up. 19 children dropped out because their parents didn't want to expose them anymore to memories of the traumatic event or because some parents raising a number of young children cannot travel to Alexandria University for assessment. Eventually 30 children and adolescents continued the research. The burn unit staff assessed the type and degree of burn. Patients were all of Middle eastern Arabic ethnicity. 


\section{Molecular genetic techniques}

\section{DNA extraction}

$2 \mathrm{ml}$ of blood was collected, genomic DNA was extracted from whole blood by DNA salting out technique as described by Sambrook et al. ${ }^{14}$ DNA concentration and purity was determined by spectrophotometer by measuring its OD260 and OD 280 using the fact that 1 absorbance unit at 260 $\mathrm{nm}$ is equal to $50 \mathrm{ug} / \mathrm{ml}$ DNA. The OD260/ OD280 was 1.7 to 2 . The DNA concentration was adjusted to be around $150 \mathrm{ng} / \mathrm{ul}$.

\section{$P C R$ amplification and digestion of PCR product}

Using thermohybraid PCR express thermal cycler; a total reaction of $50 \mathrm{ul}$ was done using Nuclease free water 15 ul, DNA 100ng, D2F primer 5'-GCTGGGCTCCTACCTGAGC-3' D2Rprimer 5'-GGACCCTGTT CACTGCCAC-3', 1x PCR buffer containing Tns HCL 750mM, 200mM (NH4) 2 SO4, 0.1 $\% 20 \mathrm{Mg} \mathrm{Cl}: 3 \mathrm{mM}$ each Tag polymerase: 1 unit. Amplification done with denaturation of 95 c for 3 minutes followed by 30 cycles of $94 \mathrm{c}$ for 1 minute $55 \mathrm{c}$ for 40 seconds, $70 \mathrm{c}$ for 30 seconds and extension of $72 \mathrm{c}$ for $10 \mathrm{~min}$ utes following amplification, $10 \mathrm{ul}$ of the PCR product is tested with $6 \mathrm{x}$ loading buffer (0.09\% bromophenol blue, 0.09 xylene cyanole, $60 \mathrm{mM}$ EDTA in $60 \%$ glycerol) and visualized on agarose gel $2 \%$ (containing Ethidium bromide $20 \mathrm{ng} / \mathrm{ul}$ ) using $50 \mathrm{bp}$ DNA Ladder and the product alter that is subjected to electrophoresis then visualized on the U/V trasilluminator. PCR product digested using Taq 1 restriction enzyme in a total volume of $30 \mathrm{ul}: 11.5 \mathrm{ul}$ nuclease free water, 15 ul pcr product, buffer tango 3 ul and restriction enzyme $0.5 \mathrm{ul}$. The product is kept in the incubator at temp $65 \mathrm{c}$ overnight then visualized on $3 \%$ agarose gel containing ethiduim bromide by the use of electrophoresis and U/V transilluminatior. The PCR product is of size $310 \mathrm{bp}$. A1A2 genotype: appear as three bands of sizes 310, 180, 130 bp. A2A2 genotype: 2 bands of sizes (130, 180 bp). A1A1 genotype: uncut 310 bp.

\section{Reevaluation phase}

Patients were reevaluated 3 and 6 months after exposure to trauma by competent board certified psychiatrists who were blinded to the genotypes of patients. Clinical Structured Interview for DSM IV (SCID) was applied to check for PTSD diagnostic criteria.

\section{Statistical Analysis}

Data were analyzed using PC with Statistical Package for Social Sciences version 13, the 0.05 was used as cut off value for statistical significance. Due to small numbers, a non parametric test (Chi square $X^{2}$ ) was applied.

\section{Results}

Thirty children and adolescents who continued the study the mean age was $12.9 \pm$ 2.4 years $53.3 \%$ of them were boys $(n=16)$ and $46.7 \%$ were girls $(n=14)$.

Fourteen children and adolescents carried the A1A2 genotype. Of those 11 (78.6\%) developed PTSD and $3(21.4 \%)$ did not. Among the sixteen who carried the A2A2 genotype, only one (6.3\%) developed PTSD while $15(93.7 \%)$ did not. The difference was statistically significant $(\mathrm{p}<0.001)$ and a relative risk $\mathrm{RR}=12.5$. (Table $1 \&$ Figure 1$)$ 
Table 1

Association between PTSD and TaqA1 allele of the DRD2 gene

Post Traumatic Stress Disorder (PTSD)

\begin{tabular}{|c|c|c|c|}
\hline & YES & $\mathrm{NO}$ & Total \\
\hline $\mathrm{A} 1 \mathrm{~A} 2$ & $11(78.6 \%)$ & $3(21.4 \%)$ & 14 \\
\hline $\mathrm{A} 2 \mathrm{~A} 2$ & $1(6.3 \%)$ & $15(93.7 \%)$ & 16 \\
\hline \multirow[t]{2}{*}{ Total } & 12 & 18 & 30 \\
\hline & & $\mathrm{p}<0.001$ & $\mathrm{RR}=12.5$ \\
\hline
\end{tabular}

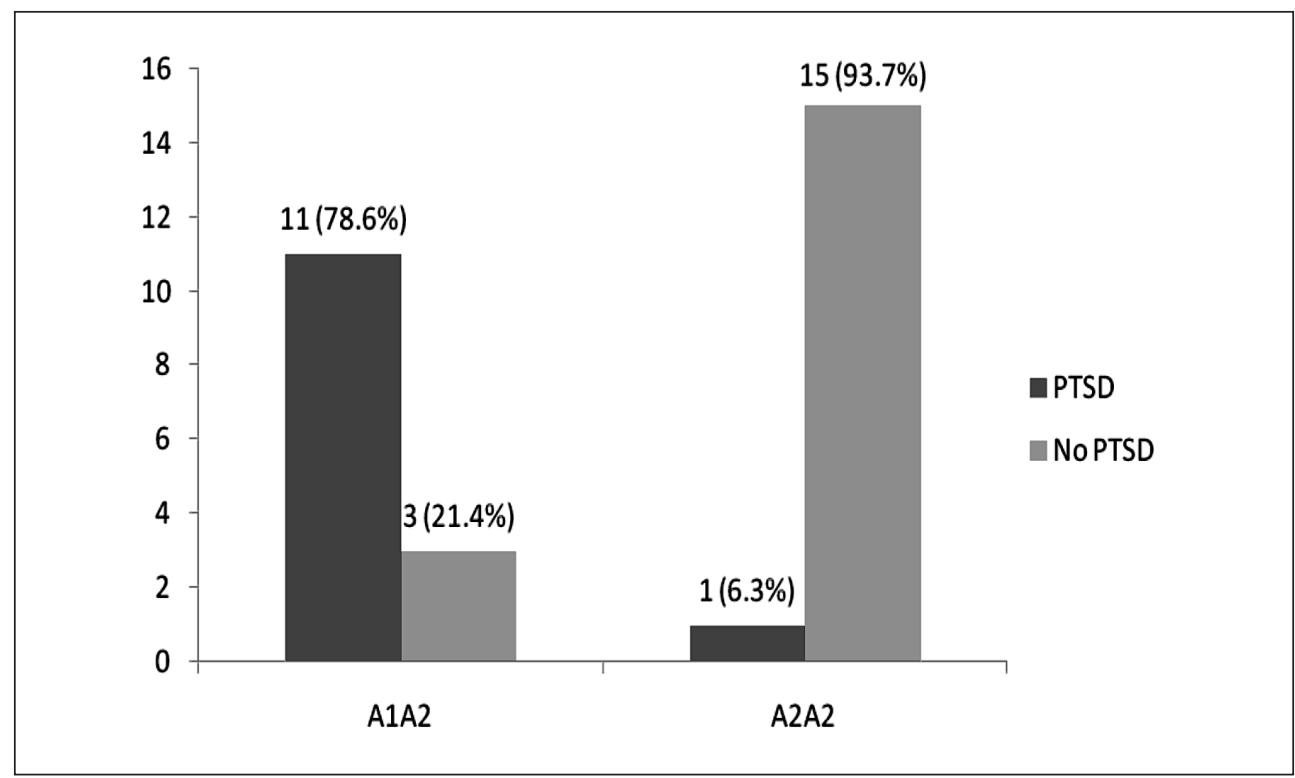

Figure 1. Association between PTSD and TaqA1 allele of the DRD2 gene

\section{Discussion}

In the current study, we found a significant association between carrying the genotype A1A2 and the development of PTSD after psychological trauma with a relative risk of 12.5 in the presence of TAqA1 allele at the DRD2 gene.

Similar to our findings, one study by Comings et al. on the role of DRD2 in PTSD re- ported a significant association between TaqA1 allele polymorphism DRD2 and risk for PTSD ${ }^{11}$. That was not confirmed in a later study carried out by Gelernter et al. research group at Yale University ${ }^{12}$. This conflicting results can be attributed to substantial difference in methodology and sampling design. In the Comings study only Vietnam veterans who had experienced traumatic battle conditions were included. Our study is similar to Comings study in terms of only recruiting 
patients who have been exposed to psychological trauma. However, Comings study sampled patients with co-morbid substance abuse disorders which may reflect a special subgroup of PTSD patients. Gelenter study, on the other hand, compared PTSD patients to healthy control group. Since both arms were not subjected to the same traumatic event, this research methodology may reflect a less sensitive way to assess increased risk to PTSD with DRD2 polymorphism after exposure to psychological trauma.

Some authors highlighted the association between TaqA1 allele polymorphism of the DRD2 gene to certain cluster of symptoms in PTSD patients, particularly Anxiety, depression and high co-morbid levels of somatic concerns ${ }^{15,16}$. Two other recent published studies tackled the association between PTSD and DRD2 gene polymorphism. Though one of them recruited 200 patients exposed to the catastrophic 1988 Spitak earthquake and revealed no association between DRD2 polymorphism and risk for PTSD. Such findings is contrary to our findings and can be attributed to ethnic difference between recruited patients. The Bailey et al. study recruited only Armenian ethnic group ${ }^{17}$.

Some authors, though highlighted a significant association between DRD2 polymorphism and risk for PTSD among war veterans, but a rather different Single Nucleotide Polymorphism (SNP) site of the coding region of ANKK1 was assessed opening new perspectives in studying the DRD2 gene in different mental health disorders ${ }^{18}$.

Though our research concerning the role of DRD2 A1 allele as a risk for PTSD is limited by the small sample size, but the point of strength in this study is that the control group has been exposed to the same traumatic event and that there is no co-morbid alcohol intake and finally there is no medication intake to alter the response of children.

\section{Conclusion}

Following exposure to severe stress, the presence of the Taq A1 allele of the DRD2 gene results in a significant increase in the risk of developing PTSD while the absence of the Taq A1 allele results in a significant decrease in the risk of developing PTSD

\section{Limitations}

A major limitation of our study is due to small samples. Since the study has been conducted on burn patients with a high mortality rate, only small percentage of patients could be followed up prospectively to assess PTSD. We do recommend replication on larger samples so that extrapolation and generalization of results can be statistically more solid.

\section{References}

1. Ventura R, Cabib S, Puglisi-Allegra S. Genetic susceptibility of mesocortical dopamine to stress determines liability to inhibition of mesoaccumbens dopamine and to behavioral despair in a mouse model of depression. Neuroscience 2002; 115: 999-1007.

2. Cabib S, Puglisi-Allegra S. Different effects of repeated stressful experiences on esocortical and mesolimbic dopamine metabolism. Neuroscience 1996; 73: 375-380.

3. Cabib S, Ventgura R, Puglisi-Allegra S. Opposite imbalances between mesocortical and mesoaccumbens dopamine responses to stress by the same genotype depending on living conditions. Behav Brain Res 2002; 129: 179-185.

4. Goldstein LE, Rasmusson AM, Bunney BS, Roth $\mathrm{RH}$. Role of the amygdala in the coordination of behavioral, neuroendocrine, and prefrontal cortical monoamine responses to psychological stress in the rat. J Neurosci 1996; 16: 4787-4798.

5. Morrow BA, Elsworth JD, Rasmusson AM, Roth RH. The role of mesoprefrontal dopamine neurons in the acquisition and expression of conditioned fear in the rat. Neuroscience 1999; 92: 553-564. 
6. Charney DS. Psychobiological Mechanisms of Resilience and Vulnerability: Implications for Successful Adaptation to Extreme Stress. Am J Psychiatry 2004; 161: 195-216.

7. Davidson J, Smith R, Krudler H. Familial psychiatric illness in chronic post traumatic stress disorder. Compr Psychiatry 1989; 30: 339-345.

8. True WR, Rice SA, Eisen J, Heath AC, Goldberg J, Lyons MJ, et al. A twin study of genetic and environmental contributions to liability for post traumatic stress symptoms. Arch Gen Psychiatry 1993; 50: 257-264.

9. Reich J, Lyons M, Cai B. Familial vulnerability factors to post traumatic stress disorder in male veterinary militants. Acta Psychiatr Scand 1996; 93: 105-112.

10. Noble EP. The DRD2 gene in psychiatric and neurological disorders and its phenotypes. Pharmacogenomics 2000; 1, 309-333.

11. Comings DE, Muhleman D, Gysin R. Dopamine D2 Receptor (DRD2) gene and susceptibility to posttraumatic stress disorder: a study and replication. Biol Psychiatry 1996; 40: 368-372.

12. Gelernter J, Southwick S, Goodson S, Morgan A, Nagy L, Charney DS. No association between D2 dopamine receptor (DRD2) 'A' system alleles, or DRD2 haplotypes, and posttraumatic stress disorder. Biol Psychiatry 1999; 45: 620-625.

13. Guidelines for service standards and severity classification in the treatment of burn injury. Appendix B to hospital resource document. ACS Bulletin 1984; 69: 25-28.
14. Sambrook J, Fritsch EF, Maniatis T. Isolation of high molecular weight DNA from mammalian cells. In: Molecular cloning. A laboratory manual (2nd ed). New York: Cold Spring Harbor Laboratory Press; 1989: p. 914-922.

15. Broekman BFP, Olff M, Boer F. The genetic background to PTSD. Neurosci Biobehav Rev 2007; 31: 348-362.

16. Lawford BR, Young R, Noble EP, Kann B, Ritchie $\mathrm{T}$. The D2 dopamine receptor (DRD2) gene is associated with co-morbid depression, anxiety and social dysfunction in untreated veterans with post traumatic stress disorder. Eur Psychiatry 2006; 21(3): 180-185.

17. Bailey JN, Goenjian AK, Noble EP, Walling DP, Ritchie T, Goenjian HA. PTSD and dopaminergic genes, DRD2 and DAT, in multigenerational families exposed to the Spitak earthquake. Psychiatry Res 2010; 178(3): 507-510.

18. Voisey J, Swagell CD, Hughes IP, Morris CP, Van Daal A, Noble EP, et al. The DRD2 gene 957C $>$ T polymorphism is associated with posttraumatic stress disorder in war veterans. Depress Anxiety 2009; 26: 28-33.

Author for correspondence:

Ahmed Rady

Lecturer of Psychiatry at Alexandria University

P.O.BOX 518 - Alexandria 21511

EGYPT

Tel.: +2 (0) 182441053

Email: dr_ahmed_rady@yahoo.fr 